\title{
Risk factors associated with bovine tuberculosis in traditional cattle of the livestock/wildlife interface areas in the Kafue basin of Zambia
}

\author{
M. Munyeme ${ }^{\text {a,* }}$, J.B. Muma ${ }^{\text {a }}$, E. Skjerve ${ }^{\text {, }}$, \\ A.M. Nambota ${ }^{\text {a }}$, I.G.K. Phiri ${ }^{\text {c }}$, K.L. Samui ${ }^{a}$, \\ P. Dorny ${ }^{\mathrm{d}}$, M. Tryland ${ }^{\mathrm{e}}$

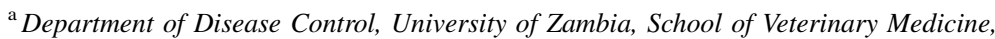 \\ P.O. Box 32379, Lusaka, Zambia \\ ${ }^{\mathrm{b}}$ Department of Food Safety and Infection Biology, Norwegian School of Veterinary Science, \\ P.O. Box 8146 Dep., 0033 Oslo, Norway \\ ${ }^{\mathrm{c}}$ Department of Clinical Studies, University of Zambia, School of Veterinary Medicine, \\ P.O. Box 32379, Lusaka, Zambia \\ ${ }^{\mathrm{d}}$ Institute of Tropical Medicine, 155 National Straat, 200 Antwerp, Belgium \\ e Section of Arctic Veterinary Medicine, Department of Food Safety and Infection Biology, \\ Norwegian School of Veterinary Science, Stakkevollveien 23, N-9010 Troms $\phi$, Norway
}

Received 17 September 2007; received in revised form 14 March 2008; accepted 14 March 2008

\begin{abstract}
We conducted a cross-sectional study from August 2003 to February 2004 to identify risk factors for bovine tuberculosis (BTB) in the Kafue basin of Zambia. We investigated a total of 106 herds of cattle for presence of BTB using the comparative intradermal tuberculin test (CITT) while an interviewer-administered questionnaire was used to gather epidemiological data on herd structure, management and grazing strategies. BTB prevalence at herd level was estimated and possible risk factors were investigated using the multiple logistic regression model. The true herd level prevalence of BTB was estimated at $49.8 \%$ (95\% CI: 37.9, 61.7\%). The logistic regression model showed that cattle herd BTB status was highly associated with area and husbandry practices. When compared to Kazungula, cattle herds in Blue Lagoon were more likely to test positive for BTB when other factors such as management practices were controlled (OR $=10.5)$. In terms of grazing strategies, transhumant herds $(\mathrm{TH})$ had higher odds $(\mathrm{OR}=3.0)$ of being positive compared
\end{abstract}

\footnotetext{
* Corresponding author. Tel.: +260 955751013; fax: +260 211293727.

E-mail address: munyeme@yahoo.co.uk (M. Munyeme).
} 
to sedentary herds $(\mathrm{OR}=1.0)$. The results in this study provide preliminary information about potential risk factors that were found to be associated with BTB status in cattle.

(C) 2008 Elsevier B.V. All rights reserved.

Keywords: Bovine tuberculosis; Cattle; Livestock/wildlife interface; Risk factors; Zambia

\section{Introduction}

Bovine tuberculosis (BTB) caused by Mycobacterium bovis (M. bovis) is a chronic, infectious and contagious disease of livestock, wildlife and humans (Holt et al., 1994; O'Reilly and Daborn, 1995). M. bovis is a major cause of animal tuberculosis and human extra-pulmonary tuberculosis (TB), especially in developing countries such as Zambia where control measures and milk pasteurization are rarely practiced (Bonsu et al., 2000). In animals, BTB is a major cause of production losses resulting from loss of production efficiency (Radostist et al., 1994). Further, losses are associated with the cost of discarding condemned meat infected with BTB. The importance of BTB as a public health problem has recently been highlighted with the advent of HIV/AIDS pandemic (Wood et al., 2000). Tuberculosis has been identified as the major and potentially lethal opportunistic infection in patients with HIV/AIDS infections leading to a serious co-infection status that accelerates the pathogenesis of both infections (Cosivi et al., 1995; Daborn et al., 1996; Grange and Yates, 1994).

Since time immemorial, the human population of the Kafue basin in Zambia has predominately practiced pastoral farming (Sitima, 1997). Cattle play very important economic and social roles in resident communities of the Kafue basin (Siamudaala et al., 2003; Sitima, 1997). However, risks of diseases especially those with zoonotic potential such as BTB are a major threat to the community welfare (Cook et al., 1996). Despite the lack of specific information from this region, cattle may be a significant source of zoonotic TB infection for man (Acha and Szyfres, 1987). Conversely, man is also increasingly becoming a risk to cattle, more of the fact that the HIV pandemic has caused a dramatic increase in the number of "open" human TB cases (Collins and Grange, 1983). A study conducted in Zambia on BTB found an association between tuberculin-positive cattle and human tuberculosis (Cook et al., 1996). The report further stated that households that had a human tuberculosis case within the previous 12 months were likely to own cattle herds containing tuberculin-positive cattle. Similarly, Daborn reports that in their investigation in neighbouring Tanzania, 7 of the 19 lymph node biopsies from suspected extra-pulmonary tuberculosis patients were infected with M. tuberculosis and four with M. bovis (Daborn et al., 1996). Other reports in the same region of Africa, in North Kivu (Zaire), documented that the frequency of human tuberculosis of animal origin was increasing with records at one time showing that out of 58 hospitalized patients, 49 were cattle herdsmen (Mposhy and Binemo-Madi, 1983). The same researchers were able to isolate $M$. bovis in two of five patients with pulmonary tuberculosis (PTB). Further studies in Zambia are underway to explore the public health significance of $M$. bovis as a source of human tuberculosis.

Cattle herds of the Kafue basin practice three types of grazing strategies. Some herds are kept within the village confines and grazed on nearby pastures. These are usually small sized herds and are known as village resident herds (VRH). At night, these herds are kept in enclosures made out of tree branches, thorn bushes, etc., while some enclosures are built 
out of barbed wire. These night enclosures are called kraals ${ }^{1}$. As herd sizes increase, most cattle owners start taking their animals to the plains during the dryer months (May to October) where grazing land is abundant. These herds return to the villages during the rain season (November to April). This practice of taking animals to flood plains in dry months is known as transhumance, and the cattle herds that practice this type of grazing strategy are known as transhumant herds $(\mathrm{TH})$. However, some transhumant herds become very large to be supported around villages, and such herds resort to permanent residence within the flood plains drawing back to higher grounds when there are floods, but without going back to the villages. Such herds are known as interface herds (IFH). In Kazungula area, only transhumant and village grazing strategies were practiced.

In some countries, a number of factors have been observed to be associated with BTB in cattle herds. A study by Oloya and others observed that BTB in Uganda was associated with different types of drinking water sources and areas of production (Oloya et al., 2007). In Eritrea, BTB was observed to be associated with communal grazing, animal breed-type, and keeping practices (Omer et al., 2001). Other studies have also shown that herd size has an influence on the prevalence of BTB (Ameni et al., 2003; Asseged et al., 2000; Cook et al., 1996; Kazwala et al., 2001, 2006). In Zambia, little is known about the factors that influence BTB status in cattle herds.

Available information on BTB in Zambian traditional cattle has been based on limited surveys restricted to reporting proportions of suspected tuberculous lesions observed at abattoir condemnations (Anon, 2000). The prevalence of BTB in Zambian livestock and wildlife, specifically the Kafue lechwe antelopes (Kobus leche Kafuensis), is reported to be high with averages of 14-30\% (Cook et al., 1996; Cosivi et al., 1998; Pandey, 1998; Sitima, 1997).

The Kafue lechwe antelope is the predominant wildlife species of the Kafue basin (Sheppe, 1985). It is a gregarious medium sized semi-aquatic antelope living in very large groups that become further concentrated during the rainy (due to floods) and dry season (due to limited grazing and watering points). It has been reported to share water and grazing pasture with cattle during the drier months of the year (Gallagher et al., 1972). When pasture grounds dwindle due to aridity and watering points remain few, the grazing range of cattle and lechwe antelopes overlap and the two animal species interact through congregating at few remaining watering points and thus facilitating possible transmission through the contamination of pasture and water sources.

During the 1967 cropping exercise ${ }^{2}$ of the Kafue lechwe at Lochinvar, 14\% (15/108) of the animals had tuberculosis, as recorded during postmortem examination. In 1972, tuberculosis lesions were found in 36\% of the hunted lechwe (Munag'andu et al., 2006; Siamudaala et al., 2003). The majority of the lechwe antelopes with visible tuberculosis lesions had primary lesions in the lungs and their draining lymph nodes.

The purpose of the present study was to describe the risk factors associated with BTB in cattle herds of the Kafue basin area of Zambia and to suggest intervention strategies for prevention and control of BTB in the area.

\footnotetext{
${ }^{1}$ A kraal may be a make shift night enclosure for keeping cattle together or it may be a semi- or permanent structure for housing cattle mainly at night when the animals are not on pasture grazing.

2 This is a legal hunting of wildlife, both males and females, to control the populations.
} 


\section{Materials and methods}

\subsection{Study areas}

We carried out a cross-sectional study in three pastoral areas of Zambia that formed three sampling strata. We conducted this study from August 2003 to February 2004. Of the three study areas, two were in the Kafue basin (Fig. 1). The Kafue basin is a floodplain of about $6000 \mathrm{~km}^{2}$ (Ghirotti et al., 1991; Munag'andu et al., 2006; Siamudaala et al., 2003) comprising Lochinvar National Park in the south $\left(410 \mathrm{~km}^{2}\right)$, Blue Lagoon National Park in the north $\left(420 \mathrm{~km}^{2}\right)$ and Kafue basin Game Management Areas $\left(5175 \mathrm{~km}^{2}\right.$ ) (Sheppe, 1985). The Kafue lechwe is the predominant wildlife species of the Kafue basin (Mwima, 1995) and is confined to a relatively small area, particularly in and around the Lochinvar and Blue Lagoon National Parks. The Kafue lechwe population is estimated at 44,000 animals (Kamweneshe et al., 2002). The interface areas of the Kafue basin National Parks are endowed with wildlife, particularly the Kafue lechwe antelope (Kobus leche Kafuensis) which easily interacts with livestock from interface and transhumant cattle herds. Kazungula District was added for comparative purposes because of similar cattle rearing practices to Blue Lagoon and Lochinvar (Fig. 1). The area has a population

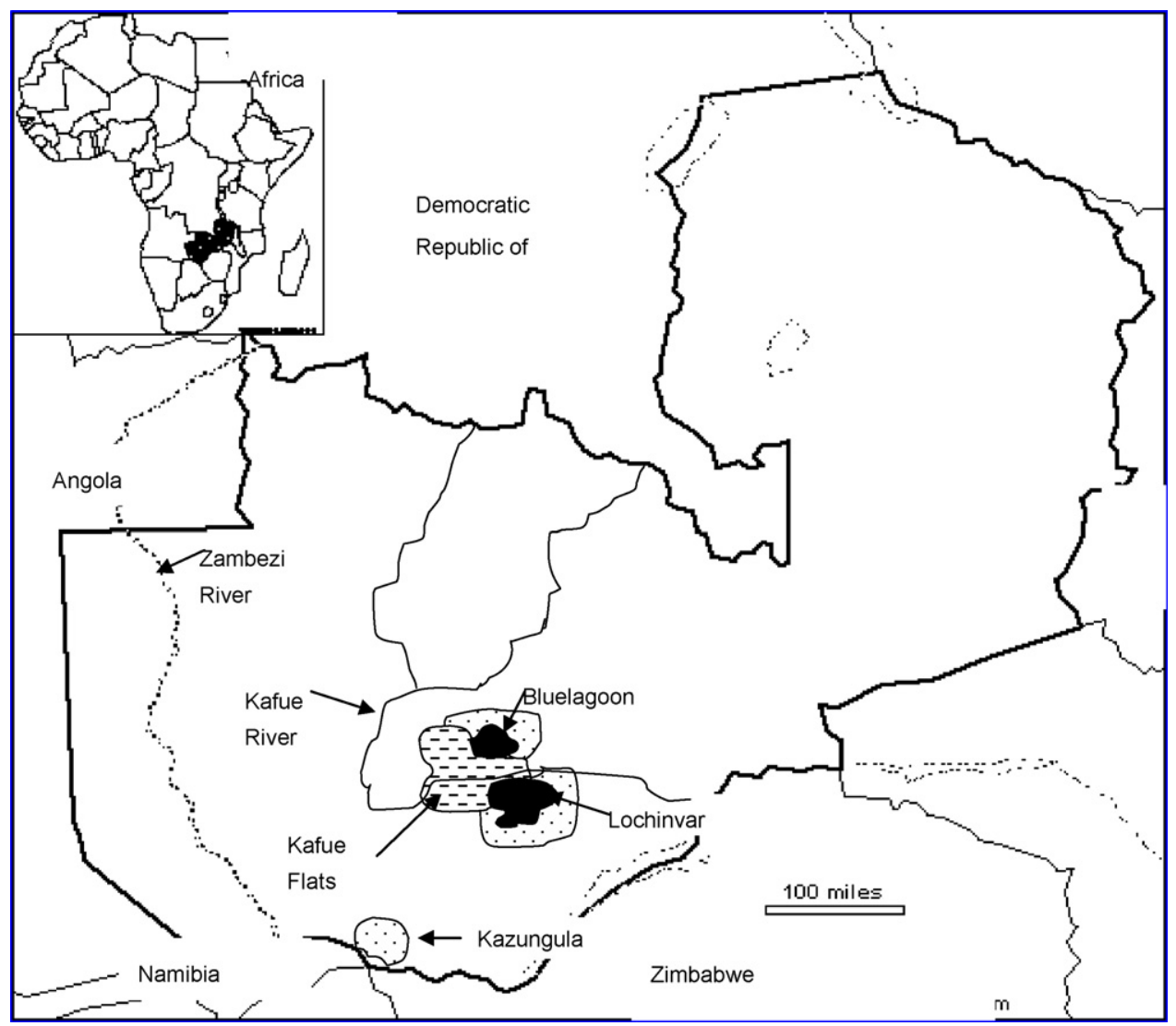

Fig. 1. Map of Zambia with all the three sampling sites of Blue lagoon and Lochinvar depicted in the interface areas and Kazungula District. 
of cattle owners who practice the transhumance grazing strategy similar to the one practiced in the Kafue basin area. This area was included to gain an insight into the TB situation in an area outside the interface of livestock/wildlife interaction. Kazungula district is located a further $400 \mathrm{~km}$ south of the Kafue basin and lies along the Zambezi River basin. It has a savannah woodland type of vegetation. Cattle in this area are outside the Game management areas (GMA) and there is no interaction with game animals.

Transhumant cattle are seasonally brought to the Kafue basin in the beginning of April and taken back to the villages early November with the onset of the rain season. On the plains, cattle share grazing land and water with lechwe and there is also significant interaction between herds coming from different parts of the Basin.

\subsection{Study design}

The study was conducted as a cross-sectional study. Due to lack of comprehensive information on the number of cattle herds $(N)$ in the study areas, a base line study was conducted. The herd was the study unit of interest and in certain cases, a 'herd' consisted of village clusters or grazing groups. In some areas, cattle ownership was quite complex, with one person having a number of cattle in various herds or different kraals. In order to increase the independency of herds, all these factors had to be considered in the herd definition. Based on the baseline study, we estimated that there were approximately 110 cattle herds in the Blue Lagoon area, 100 in Lochinvar and 50 in Kazungula. During the baseline study, all cattle owners in the targeted study areas were listed as the target population. This population of herds constituted the study population from which actual sampling was conducted (sample population).

Assuming low heterogeneity between herds, we used a detection power $(1-\beta)$ of $90 \%$, the level of significance $(\alpha)$ at $95 \%$ and the desired absolute precision at $5 \%$. We further assumed the sensitivity and specificity of the comparative intradermal tuberculin test (CITT) to be $80 \%$ and $100 \%$, respectively (Monaghan et al., 1994; Quirin et al., 2001). The BTB prevalence previously reported for cattle in Zambia varies from $10 \%$ to $20 \%$ at animal level (Cook et al., 1996; Sitima, 1997). We therefore assumed an average of $15 \%$ as BTB animal prevalence with herd level prevalence being estimated at 30\%. The average herd size was assumed to be at 100 animals. We thus planned to sample individual cattle from herds at a $10 \%$ sampling fraction. Based on these assumptions, we used Herdacc ${ }^{\mathrm{TM}}$ Version 3 (Jordan, 1995) to estimate herd specificity (HSp) and herd sensitivity (HSe). Our predicted HSp and HSe were $100 \%$ and $73.9 \%$ at $10 \%$ sampling fraction, where a herd was classified positive if at least one animal tested positive on CITT. Thus applying the estimates in the sample size calculation formula for simple random sampling, and correcting for a finite population we planned to sample 125 herds represented as 53, 48 and 24 herds for Blue Lagoon, Lochinvar and Kazungula, respectively. To select this number of herds and to avoid selection bias, a simple random mechanism of choosing herds was designed using a lottery system. In each study area, cattle herds were given numbers written on pieces of paper. These numbers were then put in a suitable receptacle from which random selection of herds was done, without replacement. In areas where farmers were un-cooperative, other herds having similar exposure factors, such as sharing grazing land and water and having similar management strategies, were chosen as replacement herds. At animal level, the situation was slightly different. For those animals that were sampled from crush pens, we used systematic random sampling, were as true random sampling was difficult to attain in animals that were restrained by casting in the kraals. 


\subsection{Intradermal skin test}

For the determination of prevalence of BTB in cattle, the comparative intradermal tuberculin test was applied. The procedure was conducted as described in the OIE manual (OIE, 2004). Two circular areas of about $2 \mathrm{~cm}^{2}$ diameter, about $12-15 \mathrm{~cm}$ apart, on the cervical area of the skin, were clipped, washed with soap and disinfected with $70 \%$ ethanol. The initial skin thickness was measured followed by an intradermal injection of $0.1 \mathrm{ml}$ of bovine and avian purified protein derivatives (PPD). The results of hyper-sensitisation were read after $72 \mathrm{~h}$ by again measuring the skin thickness. A strict standard level of interpretation was used to classify reactors according to the OIE manual (OIE, 2004). Negative reactors were indicated by increases in differential skin thickness increment of less than $2 \mathrm{~mm}$ when the avian reading was subtracted from the bovine reading. Inconclusive reactors were indicated by differential skin thickness increment of between 2 and $4 \mathrm{~mm}$, while a positive reaction was indicated by differential skin increment of more than $4 \mathrm{~mm}$. Further still, a negative reactor was identified when there was no reaction to bovine tuberculin, or a positive or inconclusive reaction to bovine tuberculin that was equal to, or less than a positive or inconclusive reaction in avian test and also when negative to both (OIE, 2004). A herd was classified positive if at least one animal in the herd tested positive on CITT.

\subsection{Questionnaire survey}

Epidemiological data was collected using a "closed-ended" pre-tested questionnaire written both in English and local language. The questionnaire was administered by "face to face" interviews mainly by the principal researcher who is a native speaker of the language spoken in the study areas. The interviews took between 20 and $30 \mathrm{~min}$ and were done at the respondent's convenience in connection to the tuberculinisation exercises. We tried to avoid interviewer variations by limiting only to two persons as interviewers. In order to improve the accuracy of the data collected during these interviews, the data relevant for the TB survey were collected simultaneously with data collected for a Brucella questionnaire (Muma et al., 2006).

\subsection{Statistical analyses}

The database was established in Excel ${ }^{\circledR}$ before transferring data to Stata SE/9 for Windows (Stata Corp., College Station, TX, USA). The database included information about sex, age, parity and body condition score at animal level. Herd level data included information about herd structure and ecological and management factors with possible influence on BTB. Herd level prevalence estimates for BTB with confidence intervals were computed using the survey command estimates in Stata with adjustments for strata (study area) as described by Dohoo et al. (2003). Estimates for individual prevelence were weighted according to primary sampling units (psu). These prevalence estimates were converted to true prevalences according to the method described by Dohoo et al. (2003), using the sensitivity and specificity assumptions as stated above. Independent effects of categorical variables on BTB herd status were assessed using the two-tailed Fisher's exact test while the effects of continuos variables were assessed by the Kruskal-Wallis test because the distribution of the variables were not normally distributed.

The potential effect of contact with wildlife, herd size, grazing strategies and other potential risk factors on the herd BTB status were examined in univariate analyses using the two-tailed Fisher's exact test. We only retained those variables that had $p$-values (two-sided) $\leq 0.25$ after checking the siginficance of the $p$-values for each variable and those without many missing 
values $(>15)$. These were the variables that we retained for multivariable analysis in a logistic model after checking for collinearity by correlation or tabular analyses. Collinearity between categorical variables was assessed using the Fisher's exact test, and for continuous data we used the correlation analysis. We manually constructed the multivariable logistic regression model using the forward selection procedure by applying the iterative maximum likelihood estimation procedure and statistical significance contribution of individual predictors (or group of predictors) to the models tested using the Walds test and the likelihood ratio test (Dohoo et al., 2003). We examined changes in the coefficients and $p$-values of the main effects to assess inclusion or exclusion. We further tested for all the possible two-way interactions by constructing the interaction product terms of the main effects, forcing them into the model and examining the changes in the likelihood ratios and the coefficients together with the $p$-values. We assessed the significance of the model using the Likelihood Ratio Test and applied the Hosmer-Lemeshow test to conduct the goodness-of-fit test.

\section{Results}

\subsection{Descriptive analysis}

Table 1 shows prevalence of BTB reactors by study area and by grazing strategy.

The true prevalence of herd level BTB was estimated at $49.8 \%$ (95\% CI: 37.9, 61.7\%) after weighting according to sampling fraction. BTB prevalence was seen to vary according to area of study with cattle herds reared in the interface areas showing high prevalence values. Most farmers investigated practiced transhumant grazing strategy $(91.5 \%)$.

\subsection{Univariable analysis at herd level}

The values that had Kruskal-Wallis or Fisher's exact $p$-value of $\leq 0.25$ were identified as potential risk factors associated with a herd having an increased risk of containing an animal that has failed a tuberculin test and were marked for inclusion in the multivariable analysis (Table 2). From cross-tabulations, area was highly associated with being transhumant and contact with wildlife and a similar association was also observed between area and whether the herds were receiving veterinary services or not; between area and type of grazing strategy; and between area and source of drinking water.

Table 1

Prevalence of bovine tuberculosis (BTB) in traditional Zambian cattle herds ( $n=106$ : August 2003 to February 2004) in three study areas according to area and different grazing patterns, calculated using the survey estimators in Stata

\begin{tabular}{llll}
\hline Variable & Study area & $\begin{array}{l}\text { Median herds } \\
\text { size (quartile range) }\end{array}$ & $\begin{array}{l}\text { Herds with BTB true } \\
\text { prevalence }(95 \% \\
\text { confidence interval) }\end{array}$ \\
\hline Study area & Blue Lagoon & $45(28,80)$ & $64.8 \%(45.3,84.3)$ \\
& Lochinvar & $51(30,89)$ & $58.1 \%(35.2,80.5)$ \\
Kazungula & $62(36,122)$ & $5.9 \%(0,16.5)$ \\
Grazing strategy & Village $(n=7)$ & $42(39,106)$ & $38.7 \%(0,84.9)$ \\
& Transhumant $(n=97)$ & $51(35,89)$ & $51.6 \%(39.2,64)$ \\
& Interface $(n=2)$ & $61(26,95)$ & Not determined \\
& Overall $(n=106)$ & $51(35,89)$ & $49.8 \%(37.9,61.7)$ \\
\hline
\end{tabular}

True prevalence estimates are given as prevalence with $95 \%$ confidence interval. 
Table 2

Raw data indicating factors associated with bovine tuberculosis (BTB) in traditional Zambian cattle herds $(n=106$; August 2003 to February 2004) tested with the comparative intradermal tuberculin test (CITT)

\begin{tabular}{|c|c|c|c|c|}
\hline Risk factor variable & Levels & $\begin{array}{l}\text { Number of } \\
\text { herds tested }\end{array}$ & $\begin{array}{l}\text { Number of } \\
\text { cattle tested }\end{array}$ & $\begin{array}{l}\text { BTB reactor } \\
\text { herds }(\%)\end{array}$ \\
\hline \multirow[t]{3}{*}{ Area* } & 1. Blue Lagoon & 48 & 490 & 48 \\
\hline & 2. Lochinvar & 35 & 280 & 43 \\
\hline & 3. Kazungula & 23 & 174 & 4 \\
\hline \multirow[t]{3}{*}{ Grazing Strategies } & Village & 7 & 368 & 29 \\
\hline & Transhumant & 97 & 326 & 38 \\
\hline & Interface & 2 & 250 & - \\
\hline \multirow[t]{4}{*}{ Herd size } & $10-35$ & 31 & 227 & 39 \\
\hline & $36-50$ & 22 & 312 & 27 \\
\hline & $51-90$ & 31 & 167 & 45 \\
\hline & $>90$ & 22 & 238 & 32 \\
\hline \multirow[t]{2}{*}{ Transhumant* } & No & 49 & 485 & 20 \\
\hline & Yes & 57 & 459 & 51 \\
\hline \multirow[t]{2}{*}{ Contact with wild animals } & No & 51 & 485 & 22 \\
\hline & Yes & 55 & 459 & 51 \\
\hline \multirow[t]{2}{*}{ Share water and grazing with wild animals } & No & 52 & 485 & 25 \\
\hline & Yes & 54 & 459 & 48 \\
\hline \multirow[t]{2}{*}{ Recieve veterinary services* } & No & 87 & 250 & 31 \\
\hline & Yes & 19 & 694 & 63 \\
\hline
\end{tabular}

Note: $*$ These values had Kruskal-Wallis or Fisher's exact $p$-value $\leq 0.25$ and were identified as risk factors for inclusion in the multivariable analysis.

\subsection{Regression analysis}

The multiple logistic regression model identified geographical area, being transhumant, and receiving veterinary services as factors having significant effect on herd BTB status (Table 3). The Hosmer-Lemeshow goodness-of-fit check showed that the model fitted the data well with $n=106, \chi^{2}(5)=4.5$ and $p=0.48$. Area had a significant effect on BTB status $(\mathrm{OR}=10.5)$ given

Table 3

Herd-level risk factors for bovine tuberculosis (BTB) in traditional Zambian cattle herds $(n=106)$ in Zambia (August 2003 to February 2004)

\begin{tabular}{|c|c|c|c|c|c|c|}
\hline Variable & Level & $b$ & $\operatorname{SE}(b)$ & $p$-value & OR & $\begin{array}{l}95 \% \text { confidence } \\
\text { interval }(\mathrm{OR})\end{array}$ \\
\hline Constant & & 2.3 & 1.1 & 0.03 & - & - \\
\hline \multirow[t]{3}{*}{ Area } & Kazungula & - & & - & 1 & - \\
\hline & Blue Lagoon & 2.3 & 11.5 & 0.03 & 10.5 & $1.2,89.7$ \\
\hline & Lochinvar & 1.8 & 7 & 0.12 & 6.1 & $0.6,58.3$ \\
\hline \multirow[t]{2}{*}{ Transhumant } & No & - & & - & 1 & - \\
\hline & Yes & 1.1 & 1.6 & 0.04 & 3.0 & $1.1,8.6$ \\
\hline \multirow[t]{2}{*}{ Receiving veterinary services } & No & - & & - & 1 & - \\
\hline & Yes & -0.94 & 0.2 & 0.09 & 0.4 & $0.1,1.2$ \\
\hline
\end{tabular}

Results from the final multivariable logistic regression model. 
that the type of grazing strategy and access to veterinary services are controlled. Similarly, transhumant grazing strategy had significant effect on BTB status $(\mathrm{OR}=3.0)$ given that area and access to veterinary services are controlled. Access to veterinary services was found to have a protective effect on BTB herd status $(\mathrm{OR}=0.4)$ given that the other two variables in the model are controlled. Although there were indications of interaction between being transhumant and receiving veterinary services, we could not include the interaction term in the model due to the effects it had on dropping the values of the odds ratios while raising the $p$-values of the main effect variables making them insignificant.

\section{Discussion}

This is the first systematic study on risk factor assessment in Zambia on cattle BTB conducted in the livestock/wildlife interface areas of the Kafue basin. The study has established the levels of BTB in cattle with different grazing strategies in the livestock/wildlife interface areas of the Kafue basin. We identified significant risk factors associated with herd BTB status in Blue Lagoon, Lochinvar and Kazungula. We did not sample all the herds according to the sampling plan. However, the number of un-sampled herds was too small $(n=3)$ to affect the validity of our results. The sensitivity (Se) and specificity ( $\mathrm{Sp}$ ) used to estimate sample size were derived from studies done in other countries and it is possible that these test parameters may not be true for our study area and may have introduced bias in sample size estimation. However, we did not expect gross departures to these estimates despite absence of information about Se and Sp of BTB in Zambian cattle. Further, although some form of clustering may have existed at herd level, we did not adjust for this effect during sample size determination. While it is difficult to state how this could have influenced our results, it is unlikely that this clustering could change the interpretation of our results.

The observed association between area and other variables may suggest the existence of an ecological linkage. Area could be a proxy variable for other risk factors such as communal grazing and contact with wildlife. Lochinvar and Blue Lagoon, receive cattle from different places around the basin which congregate on the plains. This arrangement potentially increases the risk of between and within herd contacts and has been documented as the key risk factor for BTB transmission in the basin (Cook et al., 1996). However, communal grazing was also practiced in Kazungula along the Zambezi plains despite the recorded low prevalence, suggesting that additional factors other than communal grazing could account for the observed differences in disease frequency. Other reports have attributed the high prevalence of BTB in cattle in the Kafue basin to the contact that exists between cattle and wild animals, particularly the lechwe antelopes (Cook et al., 1996; Cosivi et al., 1998; Pandey, 1998; Sitima, 1997). Some reports have described the Kafue lechwe antelope as a reserviour/source of source of an un-treatable BTB (Gallagher et al., 1972; Pandey, 1998; Stafford, 1991). Pandey (1998) postulated that cattle on the plains could acquire BTB through grazing contaminated pastures (Pandey, 1998). Wildlife reservoirs of $M$. bovis have been reported to be major sources of infection for grazing cattle in some countries (Corner, 2006), such as the badger (Meles meles) in regions of the United Kingdom and possums (Trichosurus vulpecula) in New Zealand (Corner, 2006; Lesslie and Brin, 1970; O'Reilly and Daborn, 1995). We observed that herds in Blue Lagoon and Lochinvar were more likely to contain animals that failed a tuberculin test in comparison to Kazungula District (Table 3) which had no livestock/wildlife interaction. Since Blue Lagoon and Lochinvar are located in the GMA, sharing of grazing land and water between cattle and lechwe is common. Moreover, BTB prevalence in lechwe has been estimated at $36 \%$ based on postmortem examinations 
(Munag'andu et al., 2006; Siamudaala et al., 2003). The prevalence of BTB is expected to be even higher when considering that not all BTB infections are detected during postmortem owing to the low sensitivity of this diagnostic tool (Pandey, 1998). Therefore in this context reduction of livestock/wildlife contact could possibly reduce exposure of cattle to suspected sources of BTB infections and farmers should therefore be discouraged from sharing grazing land and watering points with wildlife.

Transhumant herds were associated with increased BTB status. This was also the most common type of management system which is also associated with multiple herd contacts increasing the risk of exposure (Ghirotti et al., 1991). In the Kafue basin, it was noted that before the onset of the annual migrations to or from the flood plains, transhumant cattle herds pooled at common sites for safety as the herdsmen have to cross-National Parks as they drove their animals to and from grazing areas each year creating the multiple herd contact necessary for increased exposure risk. Up to more than eight large herds could mix for this purpose. Being transhumant is a known risk factor for infectious disease transmission and farmers should therefore be encouraged to adopt management strategies that reduce in between or multiple herd contacts (MacPherson, 1995).

Access to veterinary services was found to be protective, although this variable was marginally significant. This was because most cattle owners that sought veterinary services had village resident herds and these accounted for less than $7 \%$ of the total herds surveyed. Farmers that sought veterinary services were more likely to get advice on the health status of their animals, and were possibly able to cull diseased animals as a control measure and thus reducing the levels of infection in the herd.

\section{Conclusion}

The results in this study provide preliminary information about potential risk factors that were found to be associated with BTB status in cattle. Therefore, future control strategies of BTB should consider area of livestock production and the types of grazing strategies as important risk factors to take into account.

\section{Acknowledgements}

We are grateful to The Norwegian Centre for International Cooperation in Higher Education (SIU) and the Norwegian Programme for Development, Research and Education (NUFU) for financial support of this project. We also acknowledge the financial support through the University of Zambia and the Flemish Inter University Council (VLIR) Project under the Belgium Inter University Cooperation at the University of Zambia (UNZA-VLIR IUC programme). We acknowledge the support and cooperation we received from herd owners and many other institutions and individuals who contributed positively to this work.

\section{References}

Acha, P.N., Szyfres, B., 1987. Zoonotic tuberculosis. In: Zoonoses and Communicable Diseases Common to Man and Animals, Pan American Health Organization/World Health Organization, Washington.

Ameni, G., Ameni, K., Tibbo, M., 2003. Bovine tuberculosis: prevelance and risk factor assessment in cattle and cattle owners in Wuchale-Jida district central Ethopia. J. Appl. Res. Vet. Med. 1, 1-4.

Anon, 2000. Annual report of the department of research and specialist services. Lusaka, Government Printers.

Asseged, B., Lubke-Becker, A., Lemma, E., Taddele, K., Britton, S., 2000. Bovine tuberculosis: a crosssectional and epidemiological study in and around Addis Ababa. Bull. Anim. Health Prod. Afr. 48, 71-80. 
Bonsu, O.A., Laing, E., Akanmori, B.D., 2000. Prevalence of tuberculosis in cattle in the Dangme-West district of Ghana, public health implications. Acta Trop. 76, 9-14.

Collins, C.H., Grange, J.M., 1983. A review. The bovine tubercle bacillus. J. Appl. Bacteriol. 55, $13-29$.

Cook, A.J., Tuchili, L.M., Buve, A., Foster, S.D., Godfrey-Fausett, P., Pandey, G.S., McAdam, K.P., 1996. Human and bovine tuberculosis in the Monze District of Zambia-a cross-sectional study. Br. Vet. J. 152, 37-46.

Corner, L.A.L., 2006. The role of wild animal populations in the epidemiology of tuberculosis in domestic animals: how to assess the risk. Vet. Microbiol. 112, 303-312.

Cosivi, O., Meslin, F.X., Daborn, C.J., Grange, J.M., 1995. Epidemiology of Mycobacterium bovis infection in animals and humans, with particular reference to Africa. Rev. Sci. Tech. 14, 733-746.

Cosivi, O., Grange, J.M., Daborn, C.J., Raviglione, M.C., Fujikura, T., Cousins, D., Robinson, R.A., Huchzermeyer, H.F., de Kantor, I., Meslin, F.X., 1998. Zoonotic tuberculosis due to Mycobacterium bovis in developing countries. Emerg. Infect. Dis. 4, 59-70.

Daborn, C.J., Grange, J.M., Kazwala, R.R., 1996. The bovine tuberculosis cycle—an African perspective. Soc. Appl. Bacteriol. Symp. Ser. 25, 27S-32S.

Dohoo, I., Martin, W., Stryhn, H., 2003. Veterinary Epidemiologic Research. AVC, Charlottetown, Canada, pp. 35-42.

Gallagher, J., MacAdam, I., Sayer, J., van Lavieren, L.P., 1972. Pulmonary tuberculosis in free-living Lechwe antelope in Zambia. Trop. Anim. Health Prod. 4, 204-213.

Ghirotti, M., Semproni, G., De Meneghi, D., Mungaba, F.N., Nannini, D., Calzetta, G., Paganico, G., 1991. Seroprevalences of selected cattle diseases in the Kafue flats of Zambia. Vet. Res. Commun. 15, 25-36.

Grange, J.M., Yates, M.D., 1994. Zoonotic aspects of Mycobacterium bovis infection. Vet. Microbiol. 40, $137-151$.

Holt, G.J., Kreig, N.R., Sneath, P.H., Staley, T.J., Williams, S.T., 1994. Bergey’s Manual of Determinative Bacteriology. Williams and Wilkins, Baltimore, U.S.A., pp. 597-603.

Jordan, D., 1995. Herdacc: A Program for Calculating Herd Level (Aggregate) Sensitivity and Specificity. Department of population medicine, University of Guelph, Guelph, O.N., Canada.

Kamweneshe, B., Beilfesus, R., Simukonda, C., 2002. Population and Distribution of the Kafule Lechwe and Other Large Mammals on the Kafue flats. Lusaka WWF Parteners for Wetlands, Zambia, p. 23.

Kazwala, R.R., Kambarage, D.M., Daborn, C.J., Nyange, J., Jiwa, S.F., Sharp, J.M., 2001. Risk factors associated with the occurrence of bovine tuberculosis in cattle in the Southern Highlands of Tanzania. Vet. Res. Commun. 25, 609-614.

Kazwala, R.R., Kusiluka, L.J., Sinclair, K., Sharp, J.M., Daborn, C.J., 2006. The molecular epidemiology of Mycobacterium bovis infections in Tanzania. Vet. Microbiol. 112, 201-210.

Lesslie, I.W., Brin, K.J., 1970. Mycobacterium avium infections in cattle and pigs in Great Britain. Tubercle 51, 446-451.

MacPherson, 1995. The effect of transhumance on the epidemiology of diseases. Prev. Vet. Med. 25, $213-224$.

Monaghan, M.L., Doherty, M.L., Collins, J.D., Kazda, J.F., Quinn, P.J., 1994. The tuberculin test. Vet. Microbiol.40, $111-124$.

Mposhy, M., Binemo-Madi, C.B.M., 1983. Influence of bovine tuberculosis on the health of the human population of North kivu (Zaire). Rev. Elev. Med. Vet. Trop. 36, 15-18.

Muma, J.B., Samui, K.L., Siamudaala, V.M., Oloya, J., Matop, G., Omer, M.K., Munyeme, M., Mubita, C., Skjerve, E., 2006. Prevalence of antibodies to Brucella spp. and individual risk factors of infection in traditional cattle, goats and sheep reared in livestock-wildlife interface areas of Zambia. Trop. Anim. Health Prod. 38, 195-206.

Munag'andu, H.M., Siamudaala, V.M., Nambota, A., Bwalya, J.M., Munyeme, M., Mweene, A.S., Takada, A., Kida, H., 2006. Disease constraints for utilization of the African buffalo (Syncerus caffer) on game ranches in Zambia. Jpn. J. Vet. Res. 54, 3-13.

Mwima, H.K., 1995. Wildlife research and management in Zambia with special reference to some protected areas where wild and domestic animals co-exist. In: The Effects of Enlargement of Domestic Animal Pasture on the Wildlife in Zambia, Lusaka, Zambia, pp. 44-64.

O'Reilly, L.M., Daborn, C.J., 1995. The epidemiology of Mycobacterium bovis infections in animals and man: a review. Tuber. Lung Dis. 76 (Suppl. 1), 1-46.

OIE, 2004. Manual of diagnostic tests and vaccines for terrestial animals Office International Des Epizooties, Paris, France.

Oloya, J., Muma, J.B., Opuda-Asibo, J., Djonne, B., Kazwala, R., Skjerve, E., 2007. Risk factors for herd-level bovinetuberculosis seropositivity in transhumant cattle in Uganda. Prev. Vet. Med. 80, 318-329.

Omer, M.K., Skjerve, E., Woldehiwet, Z., Holstad, G., 2001. A cross-sectional study of bovine tuberculosis in dairy farms in Asmara, Eritrea. Trop. Anim. Health Prod. 33, 295-303.

Pandey, G.S., 1998. Studies of the Infectious Diseases of the Kafue Lechwe (Kobus Leche Kafuensis) with Particular Reference to Tuberculosis in Zambia. Azabu University, Tokyo.

Quirin, R., Rasolofo, V., Andriambololona, R., Ramboasolo, A., Rasolonavalona, T., Raharisolo, C., Rakotoaritahina, H., Chanteau, S., Boisier, P., 2001. Validity of intradermal tuberculin testing for the screening of bovine tuberculosis in Madagascar. Onderstepoort J. Vet. Res. 68, 231-238. 
Radostist, O.M., Blood, D.C., Gay, C.C., 1994. Veterinary Medicine, Eighth ed. Bailliere Tndall, London.

Sheppe, W.A., 1985. Effects of human activities on Zambia's Kafue flats ecosystmes. Environ. Conserv. J. 12, $49-57$.

Siamudaala, V.M., Muma, J.B., Munag'andu, H.M., Mulumba, M., 2003. Veterinary challenges regardding the utilisation of the Kafue lechwe (Kobus leche kafuensis) in Zambia. In: Conservation and Development Interventions: At the Wildlife/Wildlife Interface: Implication for Wildlife, Livestock and Human Health, Durban, South Africa, 14th to 15th August, pp. 75-80.

Sitima, A.C., 1997. Variability of Mycobacterium Bovis in Traditionally Processed Sour Milk and the Prevalence of Bovine Tuberculosis in Namwala District of Zambia. University of Zambia, Lusaka.

Stafford, K.J., 1991. A review of diseases of parasites of the Kafue lechwe (Kobus leche kafuensis). J. Wildl. Dis. 27, 661667.

Wood, R., Maartens, G., Hudson, C.P., 2000. Diagnosising HIV associated tuberculosis: reducing the costs and diagnostic delays. Int. J. Tuberc. Lung Dis. 4, 240-245. 